\title{
ASPECTOS FUNCIONAIS, DE SAÚDE E TECNOLÓGICOS DE FRUTANOS TIPO INULINA
}

\author{
TATIANA COLOMBO PIMENTEL* \\ SANDRA GARCIA** \\ SANDRA HELENA PRUDENCIO***
}

\begin{abstract}
Esta revisão teve como objetivos definir adequadamente os diferentes frutanos tipo inulina, discutir seus principais benefícios à saúde e expor as aplicações tecnológicas desses ingredientes. A proposta de classificar adequadamente os diversos frutanos tipo inulina assume importância para efeito de controle regulatório e para evitar incerteza ou confusão do consumidor. Dentre os benefícios à saúde que podem ser proporcionados pela ingestão de frutanos tipo inulina há pesquisas que apresentam resultados disponíveis e confirmatórios em humanos, comprovando as alegações de melhoria das funções intestinais e da microbiota colônica e aumento na absorção de minerais. Outras relatam resultados experimentais convincentes e estudos preliminares com humanos, sendo necessários mais testes a fim de substanciar as alegações que envolvem o metabolismo do colesterol e a redução de câncer de cólon. Também há pesquisas em fase de investigações experimentais e com testes iniciais com humanos que avaliam a saúde dos ossos, produção de nutrientes e regulação da ingestão de alimentos. Tecnologicamente, frutanos tipo inulina são usados pela indústria alimentícia como suplementos em alimentos, aumentando o teor de fibras dos produtos, e como substitutos de macronutrientes como gordura e açúcar. Concluiu-se que frutanos tipo inulina são ingredientes que oferecem combinação única de propriedades funcionais, de saúde e tecnológicas, podendo ser utilizados amplamente pela indústria alimentícia. É importante, no entanto, classificá-los adequadamente e atestar sua eficácia à saúde humana no produto em que serão adicionados.
\end{abstract}

* Engenheira de Alimentos, Mestre e Doutoranda em Ciência de Alimentos pela Universidade Estadual de Londrina (UEL), Londrina, PR (e-mail: tatipimentel@hotmail.com).

** Engenheira de Alimentos, Mestre em Ciência de Alimentos, Doutora em Ciência de Alimentos, Professora Associada, UEL, Londrina, PR (e-mail: sgarcia@uel.br).

*** Farmacêutica-Bioquímica, Mestre em Ciência de Alimentos, Doutora em Ciência de Alimentos, Professora Associada, UEL, Londrina, PR (e-mail: sandrah@uel.br). 


\section{INTRODUÇÃo}

Determinado alimento pode ser considerado funcional se for demonstrado satisfatoriamente que afeta beneficamente uma ou mais funções do organismo, além da finalidade nutricional, de modo que seja relevante na melhoria do bem-estar e saúde e/ou redução do risco de doença (ROBERFROID, 2005a). Dentre os principais nichos de desenvolvimento dos alimentos funcionais, a fisiologia do intestino grosso e a atividade da microbiota que o coloniza têm atraído grande interesse, com maiores desenvolvimentos na área de probióticos, prebióticos e simbióticos (ROBERFROID, 2005b).

Prebióticos são componentes alimentares não viáveis que conferem benefícios à saúde do hospedeiro, associados à modulação de sua microbiota (FAO/AGNS, 2007). Entre esses, frutanos tipo inulina são únicos devido à sua natureza química e seus efeitos sobre as funções gastrointestinais (ROBERFROID, 2005b).

Frutanos tipo inulina podem ser usados tanto como suplemento em alimentos, quanto como substitutos de macronutrientes (COUSSEMENT, 1999). Como suplementos, são adicionados em razão de suas propriedades nutricionais, aumentando o teor de fibra dos produtos. Por não apresentarem sabores residuais e não contribuírem significativamente para a viscosidade dos alimentos é possível utilizá-los em concentrações elevadas, originando produtos com alta concentração de fibras e semelhantes em aparência e sabor aos convencionais (NINESS, 1999). Em outras aplicações, são adicionados para permitirem alegações de propriedade funcional ou de saúde específicas como aquelas relacionadas à atividade bifidogênica. Como substitutos de macronutrientes, inulina e oligofrutoses ou frutooligossacarídeos (FOS) são utilizados para substituir gordura e açúcar, respectivamente (COUSSEMENT, 1999).

Considerando a relevância do tema justifica-se a proposta desta revisão de apresentar informações acerca de frutanos tipo inulina, discutir seus principais benefícios à saúde e expor aplicações tecnológicas desses ingredientes.

\section{ASPECTOS GERAIS}

Os carboidratos tipo inulina integram a classe denominada frutanos, aqueles polímeros em que uma ou mais ligações frutosil-frutose representam a maioria das ligações glicosídicas, sendo seu grau de polimerização (DP) determinado por meio do número de unidades individuais de monossacarídeos que compõem a molécula (CARABIN e FLAMM, 1999; KELLY, 2008). O grau de polimerização pode influenciar as propriedades desses ingredientes, como digestibilidade, atividade prebiótica, poder adoçante, capacidade de absorção de água, etc. (ROBERFOIRD, 2005a). Não há padrão para a nomenclatura desse tipo de frutano, sendo que os três termos genéricos encontrados mais frequentemente são inulina, oligofrutose e frutooligossacarídeo, os quais não são utilizados da mesma maneira nas pesquisas (KELLY, 2008).

$O$ termo inulina descreve misturas de frutanos que contenham pelo menos algumas cadeias com DP maior do que 10 (CARABIN e FLAMM, 1999; KELLY, 2008). A inulina, denominada convencional, tem DP médio de 10 e contém em torno de 6 a 10\% de açúcares livres, representados pela glicose, frutose e sacarose. Esses açúcares estão presentes na planta da qual a inulina foi extraída e, portanto, não resultam do processamento (NINESS, 1999).

A inulina está amplamente distribuída na natureza em várias plantas e em algumas bactérias e fungos (FRANCK, 2002). Pode ser encontrada em: alcachofra de Jerusalém, alho, arroz, aspargo, banana, cebola, centeio, cevada, dente de leão, trigo, yacon e outros vegetais (TUNGLAND, 2000; KELLY, 2008). A produção comercial ocorre a partir da extração de raízes de chicória (Cichorium intybus), preferida por conter altas concentrações de inulina (15-20\%), utilizando-se água quente 
mediante processo semelhante ao da extração de açúcar da beterraba (NINESS, 1999; FRANCK, 2002; ROBERFROID, 2005a; KELLY, 2008). O extrato bruto é, então, refinado, evaporado e liofilizado (ROBERFROID, 2005a).

A inulina denominada de "alta performance" (HP) consiste de misturas de frutanos tipo inulina exclusivamente com DP $\geq 10$ tendo, portanto, maior massa molecular (COUSSEMENT, 1999; NINESS, 1999; ROBERFROID, 2005a). Para a sua produção, moléculas de cadeia curta da inulina convencional são removidas por processos físicos (ROBERFROID, 2005b).

Quanto às oligofrutoses e os frutooligossacarídeos (FOS), alguns pesquisadores os consideram como sendo termos sinônimos, designando misturas de frutanos tipo inulina com DP máximo de 10 (CRITTENDEN e PLAYNE, 1996; FRANCK, 2002; ROBERFROID, 2005a). No entanto, outros definem frutooligossacarídeos como sendo os frutanos tipo inulina sintetizados a partir da sacarose, e oligofrutoses aqueles produzidos por hidrólise parcial da inulina (COUSSEMENT, 1999; CARABIN e FLAMM, 1999; VAN DE WIELE et al., 2007).

A produção de frutanos tipo inulina a partir da sacarose ocorre por meio da atividade de transfructosilação da enzima $\beta$-fructofuranosidade de Aspergillus niger. Nessa reação, a sacarose serve como substrato no qual 1,2 ou 3 unidades de frutose são adicionadas através de ligações glicosídicas $\beta-1,2$. $O$ produto resultante contém entre 2 e 4 unidades frutosil que terminam com resíduo de glicose, as quais são denominadas: 1-questose, 1-nistose e 1-frutosilnistose (DP médio de 3,6$)$. Glicose e pequenas quantidades de frutose, subprodutos da reação, assim como a sacarose residual são removidas da mistura mediante processos cromatográficos e resultam em ingredientes com alta pureza (CRITTENDEN e PLAYNE, 1996; ROBERFROID, 2005b).

Para a hidrólise enzimática parcial da inulina utilizam-se inulinases. A mistura originada por esse processo é semelhante à formada por transfructosilação, no entanto, nem todas as unidades frutosil unidas por ligações glicosídicas $\beta-1,2$ terminam com resíduo de glicose. Além disso, a mistura formada pela hidrólise da inulina contém oligômeros com cadeias mais longas do que a produzida por transfructosilação (DP médio de 4) (CRITTENDEN e PLAYNE, 1996; ROBERFROID, 2005b). Existe ainda, a combinação de inulina com alto grau de polimerização (HP) e oligofrutose, denominada Synergy 1, que foi desenvolvida a fim de oferecer os benefícios associados aos dois tipos de frutanos (GRIFFIN et al., 2003; ROBERFROID, 2005a). Tanto a inulina quanto as oligofrutoses e FOS têm valor calórico de $1,5 \mathrm{kcal} / \mathrm{g}$ (ROBERFROID, 1999).

Como não há consenso científico quanto à nomenclatura utilizada para frutanos tipo inulina, as seguintes definições são propostas:

- FOS: misturas de frutanos tipo inulina exclusivamente de cadeia curta $(\mathrm{DP}<10)$, sintetizadas a partir da sacarose;

- Oligofrutose: misturas de frutanos tipo inulina exclusivamente com DP<10 produzidas por hidrólise parcial da inulina;

- Inulina: frutanos tipo inulina que contém pelo menos algumas cadeias longas (DP $\geq 10$ ), obtidos de raízes de chicória por extração com água quente;

- Inulina HP: frutanos tipo inulina exclusivamente com cadeia longa ( $D P \geq 10$ );

- Inulina enriquecida com oligofrutose ou Synergy 1: combinação de inulina com alto grau de polimerização (HP) e oligofrutose.

Pretende-se com essa divisão classificar adequadamente os diversos frutanos tipo inulina. Além disso, considerando-se FOS e oligofrutoses como sendo compostos diferentes torna-se possível discriminar se o ingrediente utilizado foi sintetizado quimicamente a partir da sacarose ou extraído de raízes de chicória e hidrolisado parcialmente.

Vasta revisão acerca da inulina e seus derivados, relacionada à origem, aos processos de obtenção, características físico-químicas e métodos de determinação pode ser encontrada em Madrigal e Sangronis (2007). 


\section{ASPECTOS FUNCIONAIS E DE SAÚDE}

\subsection{EFEITO PREBIÓTICO}

Os prebióticos não são digeríveis, pois o hospedeiro não produz enzimas capazes de cliválos em fragmentos menores que possam ser posteriormente utilizados nos processos catabólicos e anabólicos comuns das células. Isto porque as enzimas humanas são específicas para ligações glicosídicas em configuração alfa e, como visto anteriormente, frutanos tipo inulina apresentam ligações glicosídicas em configuração beta. Consequentemente, esses carboidratos estão completamente disponíveis para a microbiota residente do trato intestinal. Alguns grupos de bactérias são estimulados, alguns não são afetados e outros são inibidos. As bactérias que são estimuladas pertencem geralmente ao grupo dos probióticos, principalmente bifidobactérias e lactobacilos (ROBERFROID, 2005a; LENOIR-WINJNKOOP et al., 2007; KELLY, 2008). As bifidobactérias exercem atividades antimicrobianas, prevenindo ou aliviando desordens gastrointestinais; têm a capacidade de modular o sistema imune; influenciam inflamações alérgicas e exercem importante papel no estabelecimento de microbiota saudável (SALMINEM, GUEIMONDE e ISOLAURI, 2005).

Muitos carboidratos não digeríveis têm sido testados como prebióticos, sendo os frutanos tipo inulina frequentemente empregados nesses estudos (TUNGLAND, 2000). Testes em humanos com dieta controlada, livre ou cruzada vêm sendo realizados, embora a dose administrada, o substrato (oligofrutose, FOS ou inulina), a duração da administração, os voluntários e os microorganismos analisados variem (ROBERFROID, 2005b).

Em diversos estudos foi encontrado aumento significativo no número de bifidobactérias após ingestão de inulina (GIBSON et al., 1995; KLESSEN et al., 1997; KOLIDA, MEYER e GIBSON, 2007), FOS (GIBSON et al., 1995; BUDDINGTON et al., 1996; BOUHNIK et al., 2007) ou oligofrutoses (MENNE, GUGGENSBUHL e ROBERFROID, 2000; RAO, 2001). Além disso, as contagens permaneceram estáveis enquanto houve a ingestão do prebiótico e decresceram progressivamente quando cessada a administração, sugerindo que o efeito benéfico associado a esses compostos persiste apenas enquanto estiverem presentes na dieta (BUDDINGTON et al., 1996; RAO, 2001; BOUHNIK et al., 2007).

Quanto ao potencial bifidogênico, não foram encontradas diferenças entre a inulina e os FOS (GIBSON et al., 1995) e entre oligofrutoses e FOS (MENNE e GUGGENSBUHL e ROBERFROID, 2000; RAO, 2001), indicando que o aumento quantitativo de bifidobactérias parece ser independente do comprimento da cadeia do frutano utilizado (ALEXIOU e FRANCK, 2008). Contudo, nem todos os derivados da inulina evidenciaram qualitativamente os mesmos efeitos sobre a microbiota intestinal e, para cada frutano tipo inulina, diferentes segmentos do intestino grosso podem ser influenciados (ROBERFROID, 2005b).

O mecanismo do efeito bifidogênico de frutanos tipo inulina tem sido relacionado à fermentação seletiva por bifidobactérias que produzem inulinases intracelulares necessárias para hidrolisar as ligações glicosídicas $\beta-1,2$ existentes entre as unidades de frutose (ROBERFROID, 2005b; ALEXIOU e FRANCK, 2008).

A dose diária do prebiótico não se correlaciona com a magnitude da resposta bifidogênica (ROBERFROID, 2005b). Em nível populacional, a eficácia do prebiótico se correlaciona com a composição basal da biota fecal e é inversamente proporcional ao número de bifidobactérias inicialmente presente no cólon (ROBERFROID, 2005b). Preconiza-se que pelo menos para alguns microorganismos específicos, a existência de organismo como componente da microbiota individual deve representar pré-condição ao estímulo do seu crescimento, sugerindo a importância da composição basal da biota fecal sobre o efeito bifidogênico (KELLY, 2008). Indivíduos com menor contagem inicial de bifidobactérias geram melhores respostas à ação dos prebióticos do que aqueles com maior contagem, possivelmente porque se um organismo está presente em quantidades baixas deve ser estimulado em maior extensão do que se estiver presente em altas contagens (TUOHY et 
al., 2001; ROBERFROID, 2005b; KOLIDA, MEYER e GIBSON, 2007; KELLY, 2008).

Gibson (2007) e Kolida, Meyer e Gibson (2007) afirmaram que a dose prebiótica de $5 \mathrm{~g} / \mathrm{dia}$ de inulina, oligofrutose ou FOS é suficiente para alterar beneficamente a microbiota colônica, sendo que em casos específicos esse valor pode chegar a $8 \mathrm{~g} / \mathrm{dia}$. Manning e Gibson (2004) verificaram que no mínimo $4 \mathrm{~g} / \mathrm{dia}$, mas preferivelmente $8 \mathrm{~g} /$ dia do prebiótico seriam necessários para aumentar significativamente a quantidade de bifidobactérias no intestino.

\subsection{AUMENTO NA ABSORÇÃO DE MINERAIS}

Verifica-se interesse crescente pela possibilidade de aumentar a absorção de minerais, especialmente o cálcio, através do consumo de prebióticos. Embora o intestino delgado seja o principal sítio de absorção de cálcio em humanos, acredita-se que quantidades significativas possam ser absorvidas ao longo de todo o intestino e, consequentemente, a maximização dos efeitos colônicos é desejável (MANNING; GIBSON, 2004).

Estudos com adolescentes (GRIFFIN, DAVILA e ABRAMS 2002; GRIFFIN et al., 2003; ABRAMS et al., 2005) e mulheres pós-menopausa (HOLLOWAY et al., 2007) confirmaram os efeitos de Sinergy 1 no aumento da absorção de cálcio e cálcio e magnésio, respectivamente. Estudos envolvendo a ingestão de oligofrutoses apresentaram resultados positivos em adolescentes (VAN DEN HEUVEL et al., 1999). Para inulina, aumento na absorção de cálcio foi observado em humanos do sexo masculino (COUDRAY et al., 1997) e mulheres pós-menopausa (KIM et al., 2004). No entanto, resultados negativos foram relatados para inulina (TEURI et al., 1999), oligofrutose (VAN DEN HEUVEL et al., 1998; GRIFFIN et al., 2002) e FOS (TAHIRI et al., 2003). As diferenças podem estar relacionadas às metodologias aplicadas para avaliação da absorção de minerais, variações na resposta aos frutanos por populações distintas, quantidade de prebióticos utilizada e níveis de cálcio da dieta (COUDRAY et al., 1997; GRIFFIN et al., 2003).

O aumento relativo na absorção intestinal do cálcio e do magnésio proporcionado pelos frutanos tipo inulina tem sido demonstrado como inversamente correlacionado com a capacidade de absorção basal, com o envelhecimento e com a duração da ingestão (COUDRAY et al., 1997; GRIFFIN et al., 2003; ROBERFROID, 2005b). Sendo assim, indivíduos com menor capacidade de absorção basal gerariam melhores respostas à ação dos prebióticos (ROBERFROID, 2005b). Como a capacidade de absorção de cálcio diminui com a idade, maiores benefícios seriam observados em pessoas idosas (ROBERFROID, 2005b). O efeito dos prebióticos sobre a absorção de minerais parece ser ótimo nas duas primeiras semanas de ingestão, decrescendo gradualmente após esse período. A explicação seria o fenômeno de regulação da via ativa de absorção de cálcio após algumas semanas de consumo (COUDRAY et al., 1997). Além disso, modificadores genéticos de absorção de cálcio também teriam efeitos relevantes, fazendo com que alguns genótipos sejam mais beneficiados com o consumo dos frutanos tipo inulina do que outros (GRIFFIN et al., 2003; ABRAMS et al., 2005).

Existem ainda evidências do efeito estimulante de frutanos tipo inulina na absorção de ferro, cobre e zinco. A magnitude desse estímulo está relacionada ao tipo de frutano utilizado, à dose empregada e ao tipo de dieta da população em estudo (SCHOLZ-AHRENS et al., 2007).

As várias hipóteses para explicar o efeito de frutanos tipo inulina na absorção de minerais são: o efeito osmótico, com a transferência da água para o intestino grosso os minerais tornam-se mais solúveis; a acidificação do conteúdo do cólon devido à fermentação e produção de ácidos graxos de cadeia curta, com posterior formação de sais solúveis de cálcio e magnésio a partir desses ácidos e consequente aumento na absorção dos minerais; e a hipertrofia da parede do cólon, aumentando a área de superfície para difusão (CARABIN e FLAMM, 1999; MUSSATO e MANCILHA, 2007). Manning e Gibson (2004) acrescentaram que o fitato (componente das plantas) é capaz de formar complexos insolúveis e estáveis com cátions divalentes, como o cálcio, tornando-os indisponíveis. A fermentação de frutanos tipo inulina aumentaria o número de bactérias capazes de metabolizar 
o fitato, liberando o cálcio e tornando-o disponível para ser absorvido. Além disso, frutanos tipo inulina têm a capacidade de aumentar a solubilidade de minerais e, consequentemente, melhoram o transporte paracelular e estimulam a troca transcelular de prótons, quando o $\mathrm{H}^{+}$intracelular é trocado pelo $\mathrm{Ca}^{2+}$ lumial (SCHOLZ-AHRENS et al., 2007).

Os resultados dos estudos acerca dos benefícios de frutanos tipo inulina na absorção de minerais sugerem que a adição desses ingredientes nos alimentos representa oportunidade de aumentar a captação de cálcio, magnésio e ferro presentes na dieta. No entanto, mais estudos são necessários para provar os seus benefícios na persistência da absorção do cálcio em longo prazo e, principalmente, se podem ser traduzidos em benefícios à saúde dos ossos (TUNGLAND, 2000; ROBERFROID, 2005b).

\subsection{ALÍVIO DA CONSTIPAÇÃO}

Estudos indicam que o consumo de frutanos tipo inulina resulta na regularização dos hábitos intestinais e alívio da constipação (HIDAKA et al., 1991; KLESSEN et al., 1997; DEN HOND GEYPENS e GHOOS, 2000; GRASTEN et al., 2003; GOTTELAND e BRUNSEN, 2006). No entanto, existem relatos de resultados não significativos (BUDDINGTON et al., 1996; VAN DOKKUM et al., 1999; CAUSEY et al., 2000). Em indivíduos constipados, a inulina, as oligofrutoses e os FOS parecem exercer papel clínico, contudo, mais pesquisas são necessárias nesse sentido (KELLY, 2009).

Há dois possíveis mecanismos de ação dos prebióticos no alívio da constipação. Primeiro, os ácidos graxos de cadeia curta, que são os produtos finais da fermentação por bactérias colônicas, de carboidratos não digeríveis como inulina, oligofrutoses e FOS, são eficientemente absorvidos e utilizados pelas células epiteliais humanas, estimulando seu crescimento e a absorção de sal e água pelo intestino. Assim, o aumento na umidade do bolo fecal através da pressão osmótica eleva a motilidade intestinal (MUSSATO e MANCILHA, 2007). Em segundo lugar, a fermentação dos prebióticos resulta em maior número de células bacterianas na massa fecal. Como o conteúdo de água das bactérias é alto ocorre aumento no conteúdo de água das fezes, provocando mudanças na sua consistência e plasticidade facilitando a excreção e elevando a frequência de evacuação (CHERBUT, 2002).

O principal efeito adverso associado à ingestão de frutanos tipo inulina é o desconforto intestinal devido à produção de gás, resultado da fermentação desses carboidratos pela microbiota colônica em condições anaeróbias (CHERBUT, 2002). No entanto, sugere-se que com dose racional de $20 \mathrm{~g} /$ dia, a distensão de gás não deve ocorrer (GIBSON, 2007). A tolerância se amplia quando a dose administrada é dividida ao longo do dia (CARABIN e FLAMM, 1999) e com o aumento do grau de polimerização (DP) do frutano utilizado (TUNGLAND, 2000).

\subsection{EFEITO NO ÍNDICE GLICÊMICO}

Muitas pesquisas vêm sendo realizadas a fim de determinar o efeito de frutanos tipo inulina na regulação do açúcar sanguíneo. Estudos com voluntários saudáveis e hiperglicêmicos não mostraram diferença na glicose plasmática ou níveis insulínicos no sangue em intervenções com inulina (VAN DOKKUM et al., 1999; LETEXIER, DIRAISON e BEYLOT, 2003), oligofrutose (ALLES et al., 1999; DAUBIOUL et al., 2005) ou FOS (LUO et al., 1996; VAN DOKKUM et al., 1999; BOUTRON-RUAULT et al., 2005), quando comparadas ao placebo. Portanto, existem evidências de que a suplementação da dieta com esses carboidratos não teria efeito positivo nos açúcares sanguíneos em indivíduos normoglicêmicos ou efeito relevante na melhoria do controle metabólico em indivíduos hiperglicêmicos (KELLY, 2009). A estagnação nos índices glicêmicos e insulínicos estaria relacionada ao fato desses carboidratos não serem hidrolisados aos seus monossacarídeos e absorvidos no intestino delgado (IZZO e NINESS, 2001). 


\subsection{EFEITO NOS LIPÍDIOS SANGUÍNEOS}

Cresce o interesse da indústria alimentícia pelo desenvolvimento de alimentos funcionais que possam modular os lipídios sanguíneos como o colesterol e os triglicerídeos (MANNING e GIBSON, 2004).

Testes em humanos têm sido realizados, tanto em indivíduos saudáveis quanto hipercolesterolêmicos ou diabéticos. Os resultados indicaram diminuição no colesterol sérico total (HIDAKA, et al. 1991; BALCAZÁR-MUÑOZ, MARTÍNEZ-ABUNDIS e GONZÁLEZ-ORTIZ, 2003; DE LUIS et al., 2010), nos níveis de triglicerídeos (CAUSEY et al., 2000; LETEXIER, DIRAISON e BEYLOT, 2003; BALCAZÁR-MUÑOZ, MARTÍNEZ-ABUNDIS e GONZÁLEZ-ORTIZ, 2003) e nos níveis de colesterol LDL (HIDAKA et al., 1991; BALCAZÁR-MUÑOZ, MARTÍNEZ-ABUNDIS e GONZÁLEZ-ORTIZ, 2003; DE LUIS et al., 2010) após ingestão de inulina, oligofrutose ou FOS. Outros estudos, no entanto, não encontraram efeito desses carboidratos nos lipídios sanguíneos (LUO et al., 1996; PEDERSEN, SANSTRÖM e VAN AMELSVOORT, 1997; ALLES et al., 1999; VAN DOKKUM et al., 1999).

As diferenças nos resultados obtidos podem estar relacionadas à variação individual, população estudada (obesos, diabéticos, hiperlipidêmicos), quantidade e duração da administração, às taxas de fermentação das diferentes frações da cadeia, à ingestão de carboidratos e gordura na dieta e aos níveis séricos de lipídios iniciais (WILLIAMS, 1999; KELLY, 2009; DE LUIS et al., 2010). No entanto, geralmente, os indivíduos hiperlipidêmicos são mais propensos a apresentar redução nos níveis de colesterol sérico quando a inulina, os FOS ou as oligofrutoses são ingeridos, enquanto indivíduos com níveis de lipídios normais são mais propensos a reduções nos níveis de triglicerídeos (WILLIAMS, 1999; TUNGLAND, 2000). Além disso, a inulina parece ser mais efetiva do que as oligofrutoses e os FOS nessas reduções (ROBERFROID, 2005b; KELLY, 2009).

Mudanças na concentração de colesterol sérico associadas aos prebóticos têm sido relacionadas com mudanças na microbiota intestinal (MUSSATO e MANCILHA, 2007). Algumas espécies de Lactobacillus e Bifidobacterium, estimuladas pelo consumo de frutanos tipo inulina, teriam capacidade de assimilar o colesterol presente no meio (TUNGLAND, 2000), enquanto outras inibiriam a absorção do colesterol via parede intestinal (TUNGLAND, 2000; MUSSATO e MANCILHA, 2007) ou produziriam metabólitos que interferem na sua síntese no fígado (GIBSON, 2007). Além disso, o aumento na desconjugação e excreção fecal de sais biliares poderiam também estar relacionados com a redução nos níveis de colesterol proporcionada por frutanos tipo inulina (DEL MORAL, MORENO-ALIAGA e HERNÁNDEZ, 2003).

Quanto aos triglicerídeos, há evidências de que os prebióticos sejam capazes de diminuir sua síntese de novo pelo fígado. Os meios pelos quais isso ocorreria ainda não estão completamente esclarecidos, mas parece que o efeito é exercido em nível transcripcional (MANNING e GIBSON, 2004). Frutanos tipo inulina reduziriam ainda a lipogênese hepática pela redução da expressão de genes codificadores de enzimas lipogênicas (ROBERFROID, 2005b). Além disso, em situações em que haja severo desbalanço da homeostase lipídica outros mecanismos podem operar, como o aumento no catabolismo de lipoproteínas ricas em triacilglicerol (ROBERFROID, 2005b).

\subsection{INIBIÇÃO DE PATÓGENOS}

Com a fermentação de frutanos tipo inulina há produção de ácidos carboxílicos de cadeia curta (acetato, butirato e propionato) e ácido lático, que servem para prover as bactérias benéficas de nutrientes e energia para seu crescimento (ROBERFROID, 1999), e diminuem o pH a valores abaixo dos quais os patógenos seriam capazes de competir efetivamente (MANNING e GIBSON, 2004; GIBSON, 2007). Haveria ainda competição por sítios de adesão e por nutrientes (GIBSON 
et al., 1995). Além disso, algumas espécies de lactobacilos e bifidobactérias são capazes de secretar antimicrobianos naturais com amplo espectro de atividade (MANNING e GIBSON, 2004; GIBSON, 2007). Lactobacillus acidophilus produz lactocidina, acidolina e acidofilina, enquanto bactérias do gênero Bifidobacterium produzem bifidolina e bifilonga (SHAH, 1999; TUNGLAND, 2000).

Manning e Gibson (2004) sugeriram que a maneira racional de reduzir casos de infecções alimentares seria a fortificação de certos componentes da microbiota intestinal para que essa se torne mais resistente à invasão, e que isso seria possível por meio do uso de prebióticos. Além disso, outras condições mais crônicas do que gastroenterites também relacionadas a patógenos podem ser susceptíveis de prevenção ou tratamento através da alteração da microbiota. Exemplos incluem a colite ulcerativa, câncer de intestino e úlcera péptica, entre outros (MANNING e GIBSON, 2004).

\subsection{PRODUÇÃO DE NUTRIENTES}

Como visto anteriormente, frutanos tipo inulina têm a capacidade de aumentar o número de bifidobactérias no cólon. Esses microrganismos são capazes de sintetizar vitaminas do complexo B (B1, B2, B6 e B12), ácido nicotínico e ácido fólico, podendo representar fonte significativa de fornecimento dessas vitaminas (MANNING e GIBSON, 2004; GIBSON, 2007). No entanto, não se tem confirmação de que o aumento do número de bifidobactérias no intestino através da utilização de frutanos tipo inulina resulte em síntese e adicional disponibilidade dessas vitaminas em humanos (TUNGLAND, 2000).

\subsection{REDUÇÃO DO RISCO DE CÂNCER DE CÓLON}

O interesse pela alteração da dieta em doenças de natureza lenta e progressiva, como o câncer de cólon, surge devido à possibilidade de influenciar a microbiota colônica por meio da alimentação (MANNING e GIBSON, 2004).

Tem sido considerado que frutanos tipo inulina com maior grau de polimerização ( $\mathrm{HP} \mathrm{e}$ Synergy 1) sejam mais ativos do que as oligofrutoses e os FOS, porque suas longas cadeias de moléculas são mais lentamente fermentadas no intestino grosso, o que prolonga seus efeitos. Já as oligofrutoses e os FOS são rapidamente e quantitativamente fermentados e nunca chegam às regiões distantes do cólon (ROBERFROID, 2005b). Inulina HP e Synergy 1 agem principalmente durante a fase de promoção do processo carcinogênico e seus efeitos envolvem a incidência, 0 rendimento e multiplicidade de focos de criptas aberrantes, tumores e até cânceres. Não reduzem apenas o número e o tamanho das lesões, mas também o risco de progressão dessas lesões para malignidade (ROBERFROID, 2005b).

De acordo com Pool-Zobel (2005), o mecanismo pelo qual prebióticos diminuiriam o risco de câncer de cólon inclui a redução da exposição a fatores de risco (carcinógenos genotóxicos) ou do seu impacto, a supressão do crescimento e da atividade metastásica das células tumorais e modulação da expressão gênica. Manning e Gibson (2004) relataram que o efeito protetor poderia estar relacionado à produção de metabólitos benéficos como o butirato, o qual estimula a apoptose de células cancerosas, e à mudança do metabolismo colônico favorecendo fermentações sacarolíticas em detrimento das proteolíticas, as quais apresentam metabólitos tóxicos e potencialmente carcinogênicos.

O efeito anticarcinogênico de frutanos tipo inulina poderia estar associado também ao aumento no número de bifidobactérias no intestino e, consequentemente, à supressão de bactérias com atividade enzimática que poderiam converter procarcinógenos em carcinógenos; redução do $\mathrm{pH}$ intestinal, modificando a atividade da microbiota e a solubilidade da bile; alteração do tempo de trânsito intestinal, removendo substâncias mutagênicas mais eficientemente; e estimulação 
do sistema imune (BUDDINGTON, 1996; TUNGLAND, 2000; KOLIDA, MEYER e GIBSON, 2007; GIBSON, 2007). No entanto, estudos in vivo têm apresentado resultados contraditórios (LIONG, 2008; KELLY, 2009). Isto pode estar relacionado à complexidade envolvida na carcinogênese, ao desenho experimental dos estudos, à dificuldade na obtenção de amostras representativas, aos diferentes estágios dos tumores nos pacientes submetidos aos estudos e à variação exercida pela utilização de diferentes frutanos tipo inulina (LIONG, 2008).

\subsection{EFEITOS NOS MECANISMOS DE DEFESA}

As funções de defesa do organismo são múltiplas, envolvendo diferentes órgãos, mecanismos e agressores potenciais. Em indivíduos saudáveis essas múltiplas funções de defesa exercem eficiente proteção. Contudo, predisposições genéticas, envelhecimento, estresse, ausência de atividade física suficiente e dieta não balanceada são fatores que podem enfraquecer essas funções e criar condições que aumentem a sensibilidade a agressões externas, tanto químicas quanto biológicas (ROBERFROID, 2005b). Um dos maiores objetivos da ciência dos alimentos funcionais é identificar componentes alimentares que tenham capacidade de modular positivamente as funções de defesa de modo a ajudar o fortalecimento, restauração e reequilíbrio dos indivíduos (ROBERFROID, 2005b).

A inulina, as oligofrutoses e os FOS influenciam positivamente o tecido linfoide associado ao intestino, o que contribui para o aumento da resistência à colonização e translocação de patógenos, acelerando a recuperação do trato gastrointestinal após distúrbios e amenizando sintomas de doenças (ALEXIOU e FRANCK, 2008). A maioria das intervenções realizadas com humanos avaliou a modulação da microbiota em indivíduos saudáveis demonstrando que frutanos tipo inulina contribuem para a manutenção da saúde e bem estar pelo aumento da função de barreira e resistência à colonização por patógenos no intestino (ALEXIOU e FRANCK, 2008).

Os prebióticos afetam diversas funções gastrointestinais mediante modulação tanto da estrutura e composição quanto das várias atividades da mucosa e da microbiota. Atuam no epitélio intestinal melhorando a morfologia e espessamento da mucosa, bem como na composição das mucinas. Como consequência, ocorre melhoria tanto química quanto enzimática das funções de defesa do trato gastrointestinal (ROBERFROID, 2005b).

\subsection{REGULAÇÃO DA INGESTÃO DE ALIMENTOS E PERDA DE PESO}

Dados experimentais têm indicado que frutanos tipo inulina, especialmente oligofrutoses e Synergy 1 , são capazes de modular hormônios intestinais envolvidos na regulação do apetite. Entre esses hormônios, o peptídeo tipo glucagon-1 (GLP-1) e a grelina têm sido investigados em estudos com animais. GLP-1, peptídeo liberado das células $L$ endócrinas-entéricas presentes no íleo e no cólon em resposta à ingestão de nutrientes, promove a secreção de insulina e a saciedade. A grelina constitui potente peptídeo orexígeno (ALEXIOU e FRANCK, 2008).

Em humanos, verificou-se que a ingestão de oligofrutose resultou no aumento da saciedade ao longo do dia e diminuição da fome e do consumo de alimentos após o jantar. Além disso, a ingestão calórica foi reduzida no café da manhã, almoço e jantar quando comparada ao tratamento controle (CANI et al., 2006). Abrams et al. (2007) observaram que a ingestão de Synergy 1 por adolescentes resultou em menores índices de massa corporal, menor ganho de peso e redução da massa gorda corpórea. Parnell e Reimer (2009) observaram perda de peso (essencialmente massa gorda) em adultos saudáveis com sobrepeso (IMC > $25 \mathrm{~kg} \mathrm{~m}^{-2}$ ) após a ingestão de oligofrutose $(21 \mathrm{~g})$ por 12 semanas. Esses resultados indicam que frutanos tipo inulina poderiam auxiliar na manutenção do peso corpóreo adequado, embora mais estudos sejam necessários para comprovar esse efeito benéfico. 


\section{ASPECTOS TECNOLÓGICOS DE FRUTANOS TIPO INULINA COMO INGREDIENTE ALIMENTAR}

Os frutanos tipo inulina alcançaram ampla aplicação na indústria alimentícia, embora não sejam adequados em refrigerantes e geleias de frutas, pois a acidez desses produtos provoca a hidrólise dos frutanos aos seus monossacarídeos com perda das propriedades físico-químicas e funcionais (VORAGEN, 1998; COUSSEMENT, 1999). O mesmo ocorre em produtos tratados termicamente a altas temperaturas ou estocados à temperatura ambiente por longos períodos (VORAGEN, 1998). Portanto, frutanos tipo inulina são estáveis em alimentos com pH superiores a 4 , e mesmo em valores menores sua hidrólise é limitada a menos de $10 \%$ se os produtos apresentarem mais do que $70 \%$ de umidade, forem estocados em temperaturas inferiores a $10^{\circ} \mathrm{C}$ ou tiverem tempo de vida útil curto (FRANCK, 2006).

Frutanos tipo inulina podem ser utilizados como suplemento em alimentos, aumentando seu teor de fibra. Fuchs, Prudêncio e Hauly (2005) suplementaram iogurtes de soja com inulina (4,43\%) e oligofrutose $(14,24 \%)$ e encontraram maiores valores de viscosidade, coesividade e adesividade e menores valores de dureza em tais produtos. Pimentel, Garcia e Prudêncio (2010a), por sua vez, suplementaram iogurtes naturais desnatados com oligofrutose, inulina e inulina HP e observaram que a adição desses componentes não influenciou os atributos de qualidade de iogurtes $(\mathrm{pH}$, acidez titulável, sinérese e firmeza). Moscatto, Prudêncio e Hauly (2004) formularam bolos de chocolate utilizando farinha de yacon e inulina como substitutos parciais da farinha de trigo e observaram que as propriedades físicas, químicas e sensoriais, bem como a estabilidade ao armazenamento dos produtos não foi alterada pela substituição. Além disso, os produtos adicionados dos ingredientes funcionais apresentaram como vantagens menores valores de dureza e maiores teores de fibra alimentar.

\subsection{PROPRIEDADES TECNOLÓGICAS DA INULINA}

A inulina está disponível comercialmente na forma de pó branco, sem odor, de sabor neutro e alta pureza. Não contém glúten, gordura, proteína e ácido fítico, podendo apresentar apenas pequenas quantidades (negligenciáveis) de alguns minerais e sais (COUSSEMENT, 1999; FRANCK, 2002; ROBERFROID, 2005a). Por conter frutose, glicose e sacarose, a inulina convencional é ligeiramente doce (10\% em relação à sacarose) enquanto a de alta performance (HP) não é. Pode ser combinada com outros ingredientes sem alterar o sabor dos produtos. É relativamente solúvel em água (máximo de 10\% à temperatura ambiente) e apresenta baixa viscosidade (menos de 2 mPa.s para solução a $5 \%$ em água) (FRANCK, 2002).

A baixa solubilidade da inulina torna-se benéfica na produção de barras de cereais com melhor estrutura e integridade a fim de manter o formato durante o processo de embalagem $e$ distribuição. Essa propriedade permite ainda a incorporação em alimentos em que outras fibras precipitariam (IZZO e NINESS, 2001).

O potencial de substituição de gordura pela inulina foi descoberto e patenteado em 1992 pela Orafti (COUSSEMENT, 1999). Em altas concentrações (> $25 \%$ para inulina convencional e $>15 \%$ para inulina HP), a inulina tem propriedade de formação de gel quando misturada à água ou leite, resultando em estrutura cremosa que pode ser incorporada em alimentos para substituir até $100 \%$ da gordura (FRANCK, 2002). O gel formado apresenta textura espalhável, sensação táctil oral homogênea, típica da presença de gordura, aspecto brilhante e liberação equilibrada de compostos de sabor na boca (ROBERFROID, 2005a). Isto se deve à habilidade da inulina de formar microcristais quando misturada à água ou leite. Esses microcristais não são percebidos na boca, mas interagem para formar textura finamente cremosa que promove a sensação de gordura (NINESS, 1999; FRANCK, 2002). A inulina HP promove duas vezes mais a sensação da gordura do que a inulina convencional (ROBERFROID, 2005a). 
A funcionalidade da inulina na substituição de gordura está baseada na sua habilidade de aumentar a viscosidade, formar gel, promover a sensação táctil oral e a textura e aumentar a capacidade de retenção de água (VORAGEN, 1998).

Em produtos espalháveis, como emulsões água-óleo ou óleo-água, a inulina permite a substituição de quantidades significativas de gordura e a estabilização da emulsão, enquanto provê textura espalhável curta. Também pode ser utilizada em produtos espalháveis, com baixo teor de gordura contendo proteínas lácteas, assim como em manteigas e outros produtos espalháveis à base de leite (FRANCK, 2002; ROBERFROID, 2005a).

O uso de inulina em produtos de panificação, cereais matinais e snacks extrusados frequentemente resulta em melhoria do sabor, da textura, da crocância, da expansão dos produtos extrusados e aumento da vida útil (FRANCK e COUSSEMENT, 1997; FRANCK, 2002). Esse ingrediente ainda melhora a umectância de pães e bolos, deixando-os frescos por mais tempo (FRANCK e COUSSEMENT, 1997; FRANCK, 2002).

Em produtos lácteos com baixo teor de gordura, como queijos frescos, cremosos ou processados, a adição de pequenas percentagens de inulina resulta em textura mais cremosa e sabor mais balanceado. Ainulina pode ser utilizada como substituto de gordura em sobremesas congeladas, promovendo fácil processamento, sensação cremosa de gordura, excelentes propriedades de derretimento e estabilidade ao congelamento e descongelamento, sem qualquer sabor residual. A substituição de gordura pela inulina pode ainda ser usada em molhos, sopas e substitutos de refeições. Na produção de produtos cárneos, como embutidos (MENEGAS, PRUDÊNCIO e GARCIA, 2004; MENEGAS et al., 2004) e patês, texturas mais cremosas e suculentas e melhor estabilidade devido à imobilização da água podem ser obtidas (FRANCK, 2002; ROBERFROID, 2005a).

A incorporação de inulina (1-3\%) em iogurtes de frutas melhora a textura e oferece efeito sinergístico de sabor em combinação com aspartame e acessulfame $\mathrm{K}$ ou ambos. Inulina HP foi utilizada como substituto de gordura em iogurtes desnatados naturais (2 g $\left.100 \mathrm{~g}^{-1}\right)$, resultando em produtos com características texturais (firmeza, coesividade, adesividade e gomosidade) e sensoriais (aceitabilidade) semelhantes aos iogurtes integrais (PIMENTEL, 2009; PIMENTEL, GARCIA e PRUDÊNCIO, 2010b; PIMENTEL, GARCIA e PRUDENCIO, 2012). Em bebidas de kefir, a adição de inulina não influenciou os atributos de qualidade dos produtos (acidez titulável, pH, cor, viscosidade, firmeza e aceitabilidade) (MONTANUCl et al., 2010).

A inulina aumenta a estabilidade de espumas e mousses e melhora a processabilidade de sobremesas lácteas aeradas. Como resultado obtém-se produtos com estrutura típica por mais tempo e com sensação semelhante à da gordura (ROBERFROID, 2005a). A inulina também pode ser incorporada em chocolates sem adição de açúcar em combinação com poliois ou frutose; como substituto de estabilizantes em diversos produtos; e em sinergia com agentes geleificantes como gelatina, alginato, carragenas e maltodextrinas (FRANCK, 2002; ROBERFROID, 2005a).

$\mathrm{Na}$ prática, ocorre substituição de cada grama de gordura por 0,25 gramas de inulina. Consequentemente, a substituição da gordura na maioria dos alimentos resultaria em concentrações de 2-6 gramas de inulina por porção (COUSSEMENT, 1999).

\subsection{PROPRIEDADES TECNOLÓGICAS DAS OLIGOFRUTOSES E DOS FOS}

As oligofrutoses e os FOS podem ser encontrados na forma de pó ou xaropes incolores (75\% matéria seca) e têm propriedades tecnológicas comparáveis às do açúcar e xaropes de glicose, por apresentarem maior quantidade de açúcares livres do que a inulina. A doçura da oligofrutose e FOS puros é de 30 a 35\% quando comparada à sacarose, consequentemente, é difícil utilizá-los sozinhos como substitutos de açúcar, sendo frequentemente combinados com edulcorantes para obtenção dos níveis de doçura desejáveis (COUSSEMENT, 1999; FRANCK, 2002) e mascarar seus 
possiveis sabores residuais (CRITTENDEN e PLAYNE, 1996). Em produtos lácteos, principalmente iogurte com frutas, melhoram o sabor das frutas, a estabilidade dos produtos e reduzem a sinérese (FRANCK, 2002; ROBERFROID, 2005a). Baixo poder adoçante é útil em alimentos nos quais agente de corpo com baixa doçura é desejável, objetivando salientar outros sabores do produto (CRITTENDEN e PLAYNE, 1996).

Comparada aos mono e dissacarídeos, a maior massa molecular das oligofrutoses e FOS faz com que haja aumento na viscosidade, resultando em encorpamento e melhoria do sabor de produtos lácteos. Também podem ser utilizados para diminuir a temperatura de congelamento de alimentos congelados; controlar o escurecimento proveniente de reações de Maillard em alimentos processados termicamente (somente FOS ou oligofrutoses que terminam com resíduo de glicose por não apresentarem terminal redutor); dar crocância a biscoitos com baixo teor de gordura ou inibir a retrogradação do amido (CRITTENDEN e PLAYNE, 1996; NINESS, 1999). Funcionam ainda como amaciantes, umectantes, aglutinantes e para expandir a vida útil em barras de cereais (CRITTENDEN e PLAYNE, 1996; IZZO e NINESS, 2001).

Os oligossacarídeos apresentam alta capacidade de retenção de água, prevenindo a secagem excessiva dos produtos e proporcionando baixa atividade de água, o que é conveniente no controle de contaminação microbiológica (CRITTENDEN e PLAYNE, 1996). Não sendo utilizados pela microbiota bucal para formar ácidos e poliglucanos podem ser empregados como substitutos de açúcar não cariogênico em gomas de mascar, iogurtes e bebidas. Como não são digeridos pelos humanos e consequentemente estagnarem os índices glicêmicos e insulínicos, tornam-se adequados para consumo por diabéticos (CRITTENDEN e PLAYNE, 1996).

\section{CONSIDERAÇÕES FINAIS}

Frutanos tipo inulina são frequentemente classificados como inulina, oligofrutoses ou FOS. Não há consenso científico quanto à definição de cada um desses termos, o que não deve representar obstáculo direto ao desenvolvimento de produtos contendo esses ingredientes, levando em consideração que os consumidores são mais atraídos pelas alegações relacionadas aos benefícios à saúde do que pelo uso de termos legais. No entanto, foram propostas na presente revisão definições explícitas que são cruciais para efeito de controle regulatório a fim de evitar incerteza e confusão.

Com relação aos benefícios à saúde proporcionados pela ingestão de frutanos tipo inulina, resultados disponíveis e confirmatórios em humanos podem ser encontrados para melhoria das funções intestinais e da microbiota colônica e aumento na absorção de minerais. Para o metabolismo do colesterol e redução de câncer de cólon, resultados experimentais convincentes e estudos preliminares disponíveis com humanos podem ser encontrados. No entanto, mais testes são necessários a fim de substanciar essas alegações. Benefícios como a melhoria da saúde dos ossos, produção de nutrientes e a regulação de ingestão de alimentos ainda estão em fase de investigações experimentais e em testes preliminares com humanos, apresentando resultados promissores.

Em alimentos, frutanos tipo inulina podem ser adicionados a fim de melhorar as características sensoriais dos produtos. As oligofrutoses e os FOS são solúveis em água e apresentam propriedades tecnológicas semelhantes às do açúcar, podendo ser utilizados em combinação com edulcorantes de alta intensidade. Já a inulina, tem a capacidade de estabilizar espumas e emulsões e exibe propriedade excepcional para a substituição de gordura.

Em conclusão, frutanos tipo inulina são ingredientes que oferecem combinação única de propriedades funcionais, de saúde e tecnológicas podendo ser utilizados amplamente pela indústria alimentícia. 


\section{ABSTRACT \\ FUNCTIONAL, HEALTH AND TECHNOLOGICAL ASPECTS OF INULIN-TYPE FRUCTANS}

This review aimed at define properly the different inulin type fructans, discuss their major health benefits and expose technological applications of these ingredients. The proposal of an appropriate classification of the various inulin type fructans is important for regulatory control purposes and also because explicit definitions are crucial to avoid uncertainty and confusion to the consumer. Regarding the health benefits that can be provided by the ingestion of inulin type fructans, it was observed that some researches presented available and confirmatory results in humans, sanctioning the claims of improvement of bowel function and colonic microbiota, and increased absorption of minerals. Other studies have reported convincing experimental results and preliminary studies with humans, however, more tests are needed to substantiate some claims, such as cholesterol metabolism and reduction of colon cancer. There are also researches in the process of experimental and preliminary tests in humans and evaluating bone health, production of nutrients and regulation of food intake. Technologically, the inulin type fructans are used by the food industry as supplements in food, thereby increasing the fiber content of products, and as a substitute for macronutrients like fat and sugar. It was concluded that inulin type fructans are ingredients that offer unique combination of functional, health and technological properties and can be widely used by the food industry. It is important, however, to classify them properly and certify their effectiveness to health in the product that they will be added.

KEY-WORDS: INULIN; OLIGOFRUCTOSE; PREBIOTIC; FUNCTIONAL FOOD.

\section{REFERÊNCIAS}

1 ABRAMS, S.A.; GRIFFIN, I.J.; HAWTHORNE, K.M.; LIANG, L.; GUNN, S.K.; DARLINGTON,G.; ELLIS, K.J. A combination of prebiotic short- and long-chain inulin-type fructans enhances calcium absorption and bone mineralization in young adolescents. American Journal of Clinical Nutrition, v. 82, n. 2, p. 471- 476, 2005.

2 ABRAMS, S.A.; GRIFFIN, I.J.; HAWTHORNE, K.M.; ELLIS, K.J. Effect of prebiotic supplementation and calcium intake on body mass index. Journal of Pediatrics, v. 151, n.3, p. 293-298, 2007.

3 ALLES, M.S.; DE ROOS, N.M.; BAKX, J.C.; VAN DE LINDONK, E.; ZOCK, P.L.; HAUTVAST, J.G.A.J. Consumption of fructooligosaccharides does not favorably affect blood glucose and serum lipid concentrations in patients with type 2 diabetes. American Journal of Clinical Nutrition, v.69, n.1, p. 64-69, 1999.

4 ALEXIOU, H.; FRANCK, A. Prebiotic inulin-type fructans: nutritional benefits beyond dietary fibre source. Nutrition Bulletin, v. 33, n.3, p. 227-233, 2008.

5 BALCAZÁR-MUÑOZ, B.R.; MARTÍNEZ-ABUNDIS, E.; GONZÁLEZ-ORTIZ, M. Efecto de la administración de inulina sobre el perfil de lipídios y la sensibilidad a la insulina en individuos com obesidad y dislipidemia. Revista Médica de Chile, v. 131, n.6, p. 597-604, 2003.

6 BOUHNIK, Y.; RASKINE, L.; CHAMPION, K.; ANDRIEUX, C.; PENVEN, S.; JACOBS, H.; SIMONEAU, G. Prolonged administration of low-dose inulin stimulates the growth of bifidobacteria in humans. Nutrition Research, v. 27, n. 4, p.187193, 2007.

7 BOUTRON-RUAULT, M.C.; MARTEAU, P.; LAVERGNE-SLOVE, A.; MYARA, A.; GEHARDT, M.F.; FRANCHISSEUR, C.; BORNET, F. Effects of a 3-mo consumption of short-chain fructo-oligosaccharides on parameters of colorectal carcinogenesis in patients with or without small or large colorectal adenomas. Nutrition Cancer, v.53, n.2, p.160-168, 2005.

8 BUDDINGTON, R.K.; WILLIAMS, C.H.; CHEN, S.C.; WITHERLY, S.A. Dietary supplement of neosugar alters the fecal flora and decreases activities of some reductive enzymes in human subjects. American Journal of Clinical Nutrition, v.63, n.5, p.709-716, 1996.

9 CANI, P.D.; JOLY, E.; HORSMANS, Y.; DELZENNE, N.M. Oligofructose promotes satiety in healthy human: a pilot study. European Journal of Clinical Nutrition, v.60, n.5, p.567-572, 2006.

10 CARABIN, I.G.; FLAMM, W.G. Evaluation of safety of inulin and oligofructose as dietary fiber. Regulatory Toxicology and Pharmacology, v. 30, n. 3, p. 268-282, 1999.

11 CAUSEY, J.L.; FEIRTAG, J.M.; GALLAHER, D.D.; TUNGLAND, B.C.; SLAVIN, J.L. Effect of dietary inulin on serum lipids, blood glucose and the gastrointestinal environment in hypercholesterolemic men. Nutrition Research, v.20, n.2, p.191201, 2000.

12 CHERBUT, C. Inulin and oligofructose in the dietary fibre concept. British Journal of Nutrition, v. 87 (Suppl. 2), p. 159$162,2002$. 
13 COUDRAY, C.; BELLANGER, J.; CASTIGLIA-DELAVAUD, C.; RÉMÉSY, C.; VERMOREL, M.; RAYSSIGNUIER, Y. Effect of soluble or partly soluble dietary fibres supplementation on absorption and balance of calcium, magnesium, iron and zinc in healthy young men. European Journal of Clinical Nutrition, v.51, p. 375-380, 1997.

14 COUSSEMENT, P.A.A. Inulin and oligofructose: safe intakes and legal status. Journal of Nutrition, v. 129, n. 7, p. 1412$1417,1999$.

15 CRITTENDEN, R.G; PLAYNE, M.J. Production, properties and applications of food-grade oligosaccharides. Trends in Food Science and Technology, v. 7, n.11, p.353-361, 1996.

16 DAUBIOUL, C.A.; HORSMANS, Y.; LAMBERT, P.; DANSE, E.; DELZENNE, N. Effect of oligofructose on glucose and lipid metabolism in patients with nonalcoholic steatohepatitis: results of a pilot study. European Journal of Clinical Nutrition, v.59, n.5, p.723-726, 2005

17 DE LUIS, D.A.; DE LA FUENTE, B.; IZAOLA, O.; CONDE, R.; GUTIÉRREZ, S.; MORILLO, M.; TORRES, C.T. Ensayo clínico aleatorizado con una galleta enriquecida en inulina en el patrón de riesgo cardiovascular de pacientes obesos. Nutrición Hospitalaria, v.25, n.1, p.53-59, 2010.

18 DEL MORAL, A.M.; MORENO-ALIAGA, M.J.; HERNÁNDEZ, J.A.M. Efecto de los prebióticos sobre el metabolismo lipídico. Nutrición Hospitalaria, v. 18, n.4, p. 181-188, 2003.

19 DEN HOND, E.; GEYPENS, B.; GHOOS, Y. Effect of high performance chicory inulin on constipation. Nutrition Research, v.20, n.5, p.731-736, 2000

20 FAO/AGNS. Food and Agriculture Organization of the United Nations/Food Quality and Standards Services. FAO Technical Meeting Report on Prebiotics. [online] Disponível em: <http://www.fao.org/ag/agn/agns/files/Prebiotics_ Tech_Meeting_Report.pdf>. 2007. Acesso em: 7 fev. 2011.

21 FRANCK, A. Inulin. In: STEPHEN, A. (Ed.). Food polysaccharides and their applications. $2^{\text {nd }}$ ed. New York: Marcel Dekker, 2006. 733 p.

22 FRANCK, A.; COUSSEMENT, P. Multi-functional inulin. Food Ingredients and Analysis International, v. 10, p. 8-10, 1997

23 FRANCK, A. Technological functionality of inulin and oligofructose. British Journal of Nutrition, v. 87, n. 2, p.287-291, 2002

24 FUCHS, R.H.B.; PRUDENCIO, S.H.; HAULY, M.C. de O. Suplementação de iogurte de soja com frutooligossacarideos: características probióticas e aceitabilidade. Revista de Nutrição, v. 18, n. 5, p. 613-622, 2005

25 GIBSON, G.R.; BEATTY, E.R.; WANG, X.; CUMMINGS, J.H. Selective stimulation of bifidobacteria in the human colon by oligofructose and inulin. Gastroenterology, v.108, n.4, p.975-982, 1995

26 GIBSON, G.R. Functional foods: probiotics and prebiotics. Culture, v. 28, n.2, p. 1-7, 2007.

27 GOTTELAND, M.R.; BRUNSEN, O.T. Efecto de un yogur con inulina sobre la función intestinal de sujetos sanos o constipados. Revista Chilena de Nutrición, v.33, n.3, p.553-560, 2006.

28 GRASTEN, S.; LIUKKONEN, K-H.; CHREVATIDISM, A.; EL-NEZAMI, H.; POUTANEN, K.; MYKKÄNEN, H. Effects of wheat pentosan and inulin on the metabolic activity of fecal microflora and on bowel function in healthy humans. Nutrition Research, v. 23, p. 1503-1514, 2003.

29 GRIFFIN, I.J.; DAVILA, P.M.; ABRAMS, S.A. Non-digestible oligossacharides and calcium absorption in girls with adequate calcium intakes. British Journal of Nutrition, v.87 (Suppl. 2), p. 187-191, 2002.

30 GRIFFIN, I.J.; HICKS, P.M.D; HEANEY, R.P.; ABRAMS, S.A. Enriched chicory inulin increases calcium absorption mainly in girls with lower calcium absorption. Nutrition Research, v. 23, n. 7, p.901-909, 2003

31 HIDAKA, H.; EIDA, T.; TAKIZAWA, T.; TOKUNAGA, T.; TASHIRO, Y. Proliferation of bifidobacteria by oligosaccharides and their useful effect on human health. Bifidobacteria Microflora, v.10, n.1, p. 65-79, 1991.

32 HOLLOWAY, L.; MOYNIHAN, S.; ABRAMS, A.; KENT, K.; HSU, A.R.; FRIEDLANDER, A.L. Effects of oligofructoseenriched inulin on intestinal absorption of calcium and magnesium and bone turnover markers in postmenopausal women. British Journal of Nutrition, v. 97, n.2, p. 365-372, 2007.

33 IZZO, M.; NINESS, K. Formulating nutrition bars with inulin and oligofructose. Cereal Foods World, v.46, n.3, p.102-106, 2001.

34 KELLY, G. Inulin-type prebiotics - a review. Part 1. Alternative Medicine Review, v.13, n.4, p.315-329, 2008.

35 KELLY, G. Inulin type prebiotics: a review. Part 2. Alternative Medicine Review, v. 14, n. 1, p. 36-55, 2009. 
36 KIM, Y.Y.; LEE, E.Y.; CHO, Y.H.; CHOUE, R.W.; JANG, K.H.; KANG, S.A.; HA, W.K. The effect of chicory fructan fiber on calcium absorption and bone metabolism in Korean postmenopausal women. Nutritional Science, v.7, n.3, p.151-157, 2004.

37 KLESSEN, B.; SYKURA, B.; ZUNFT, H.J.; BLAUT, M. Effects of inulin and lactose on fecal microflora, microbial activity, and bowel habit in elderly constipated persons. American Journal of Clinical Nutrition, v. 65, n.5, p.1397-1402, 1997.

38 KOLIDA, S.; MEYER, D.; GIBSON, G.R. A double-blind placebo - controlled study to establish the bifidogenic dose of inulin in healthy humans. European Journal of Clinical Nutrition, v. 61, n. 10, p. 1189-1195, 2007.

39 LENOIR-WINJNKOOP, I.; SANDERS, M.E.; CABANA, M.D.; CAGLAR, E.; CORTHIER, G.; RAYES, N.; SHERMAN, P.M.; TIMMERMAN, H.M.; VANEECHOUTTE, M.; VAN LOO, J.; WOLVERS, D.A. Probiotic and prebiotic influence beyond the intestinal tract. Nutrition Reviews, v. 65, n. 11, p. 469-489, 2007.

40 LETEXIER, D.; DIRAISON, F.; BEYLOT, M. Addition of inulin to a moderately high-carbohydrate diet reduces hepatic lipogenesis and plasma triacylglycerol concentrations in humans. Journal of Clinical Nutrition, v. 77, n. 3, p.559-564, 2003.

41 LIONG, M-T. Roles of probiotics and prebiotics in colon cancer prevention: postulated mechanisms and in-vivo evidence. International Journal of Molecular Science, v.9, n.5, p. 854-863, 2008

42 LUO, J.; RIZKALLA, S.W.; ALAMOWITCH, C.; BOUSSARI, A.; BLAYO, A.; BARRY, J.L.; LAFFITTE, A.; GUYON, F.; BORNET, F.R.; SLAMA, G. Chronic consumption of short-chain fructooligosaccharides by healthy subjects decreased basal hepatic glucose production but had no effect on insulin-stimulated glucose metabolism. American Journal of Clinical Nutrition, v.63, n.6, p.939-945, 1996.

43 MADRIGAL, L.; SANGRONIS, E. La inulina y derivados como ingredientes claves en alimentos funcionales. Archivos Latinoamericanos de Nutrición, v.57, n.4, p.387-396, 2007.

44 MANNING, T.S.; GIBSON, G.R. Prebiotics. Best Practice \& Research Clinical Gastroenterology, v.18, n.2, p.287-298, 2004.

45 MENEGAS, Léia Zenaide; PRUDENCIO, Sandra Helena; GARCIA, Sandra. Efeito da redução de lipídeos no pH, atividade de água, bactérias lácticas e aceitação de embutido fermentado de frango contendo óleo de milho durante o processamento. In: CONGRESSO BRASILEIRO DE CIÊNCIA E TECNOLOGIA DE ALIMENTOS: ESTRATÉGIA PARA O DESENVOLVIMENTO, 19., 2004, Recife. Anais... Recife: SBCTA, 2004. p. 1-4.

46 MENEGAS, Léia Zenaide; PRUDENCIO, Sandra Helena ; GARCIA, Sandra MERGUIZO, R.A. Efeito das culturas starter e probiótica sobre $\mathrm{pH}$, atividade de água e bactérias lácticas de um produto fermentado de frango contendo óleo de milho. In: CONGRESSO BRASILEIRO DE CIÊNCIA E TECNOLOGIA DE ALIMENTOS: ESTRATÉGIA PARA O DESENVOLVIMENTO, 19., 2004, Recife. Anais... Recife: SBCTA, 2004. p. 211-214.

47 MENNE, E.; GUGGENSBUHL, N.; ROBERFROID, M. Fn-type chicory inulin hydrolysate has a prebiotic effect in humans. Journal of Nutrition, v.130, n.5, p.1197-1199, 2000

48 MONTANUCI, Flávia Daiana.; GARCIA, Sandra; PRUDÊNCIO, Sandra Helena; PIMENTEL, Tatiana Colombo. Bebidas de kefir integral ou desnatada, com e sem inulina: caracterização química, física, microbiológica e sensorial. In: CONGRESSO BRASILEIRO DE CIÊNCIA E TECNOLOGIA DE ALIMENTOS: POTENCIALIDADES, DESAFIOS E INOVAÇÃO, 12., 2010, Salvador. Anais... Salvador: SBCTA, 2010. p. 1-1.

49 MOSCATTO, J.A.; PRUDÊNCIO, S.H.; HAULY, M.C de O. Farinha de yacon e inulina como ingredientes na formulação de bolo de chocolate. Ciência e Tecnologia de Alimentos, v. 24, n. 4, p. 634-640, 2004.

50 MUSSATTO, S.I.; MANCILHA, I.M. Non-digestible oligosaccharides: a review. Carbohydrate Polymers, v. 68, n. 3, p.587-597, 2007

51 NINESS, K.R. Inulin and oligofructose: what are they? Journal of Nutrition, v.129. n.7, p. 1402-1406, 1999.

52 PARNELL, J.A.; REIMER, R.A. Weight loss during oligofructose supplementation is associated with decreased ghrelin and increased peptide $Y Y$ in overweight and obese adults. The American Journal of Clinical Nutrition, v.89, n.6, p.1751-1759, 2009.

53 PEDERSEN, A.; SANDSTRÖM, B.; VAN AMELSVOORT, J.M.M. The effect of ingestion of inulin on blood lipids and gastrointestinal symptoms in healthy females. British Journal of Nutrition, v.78, n.2, p.215-222, 1997.

54 PIMENTEL, T.C. logurte probiótico com inulina como substituto de gordura. 2009. 154 p. Dissertação (Mestrado em Ciência de Alimentos), Universidade Estadual de Londrina, Londrina, 2009.

55 PIMENTEL, Tatiana Colombo; GARCIA, Sandra; PRUDÊNCIO, Sandra Helena. Efeito do grau de polimerização de frutanos tipo inulina sobre os atributos de qualidade de iogurtes probióticos. In: ENCONTRO REGIONAL SUL DE CIÊNCIA E TECNOLOGIA DE ALIMENTOS, 10., 2010, Curitiba. Anais... Curitiba: SBCTA, 2010a. p.1-1. 
56 PIMENTEL, Tatiana Colombo; GARCIA, Sandra; PRUDÊNCIO, Sandra Helena. Iogurte probiótico com inulina como substituto de gordura: caracterização físico-química e microbiológica durante armazenamento refrigerado e aceitabilidade. In: CONGRESSO BRASILEIRO DE CIÊNCIA E TECNOLOGIA DE ALIMENTOS: POTENCIALIDADES, DESAFIOS E INOVAÇÃO, 22., 2010, Salvador. Anais... Salvador: SBCTA, 2010b. p.1-1.

57 PIMENTEL, T.; GARCIA, S.; PRUDENCIO, S. H. Effect of long-chain inulin on the texture profile and survival of Lactobacillus paracasei ssp. paracasei in set yoghurts during refrigerated storage. International Journal of Dairy Technology, v.65, n.1, p. 104-110, 2012.

58 POOL-ZOBEL, B. Inulin-type fructans and reduction in colon cancer risk: review of experimental and human data. British Journal of Nutrition, v. 93, n. 1, p.73-90, 2005.

59 RAO, V.A. The prebiotic properties of oligofructose at low intake levels. Nutrition Research, v.21, n.6, p. 843-848, 2001

60 ROBERFROID, M. B. Caloric value of inulin and oligofructose. Journal of Nutrition, v. 129, n. 7, p. 1436-1437, 1999.

61 ROBERFROID, M. B. Inulin-type fructans: functional food ingredients. London: CRC Press, $2005 a .392$ p.

62 ROBERFROID, M. B. Introducing inulin-type fructans. British Journal of Nutrition, v. 93, n. 1, p.13-25, 2005b.

63 SALMINEN, S.J.; GUEIMONDE, M.; ISOLAURI, E. Probiotics that modify disease risk. Journal of Nutrition, v.135, n.5, p.1294-1298, 2005.

64 SCHOLZ-AHRENS, K.E. et al. Prebiotics, probiotics, and synbiotics affect mineral absorption, bone mineral content, and bone structure. Journal of Nutrition, v.137, n.3, p. 838-846, 2007.

65 SHAH, N.P. Probiotic bacteria: antimicrobial and antimutagenic properties. Probiotica, v.6, p.1-3, 1999.

66 TAHIRI, M.; TRESSOL, J.C.; ARNAUD, J.; BORNET, F.R.J.; BOUTELOUP-DEMANGE, C.; FEILLET-COUDRAY, C.; BRANDOLINI, M.; DUCROS, V.; PÉPIN, D.; BROUNS, F.; ROUSSEL, A.M.; RAYSSIGUIER, Y.; COUDRAY, C. Effect of short-chain fructooligosaccharides on intestinal calcium absorption and calcium status in postmenopausal women: a stable-isotope study. American Journal of Clinical Nutrition, v.77, n.2, p. 449-457, 2003.

67 TEURI, U.; KARKKAINEN, M.; LAMBERG-ALLARDT, C.; KORPELA, R. Addition of inulin to breakfast does not acutely affect serum ionized calcium and parathynoid hormone concentrations. Annals of Nutrition and Metabolism, v.43, n.6, p.356-364, 1999.

68 TUNGLAND, C. Inulin: a comprehensive scientific review. 2000. Online. Disponível em: < http://members.shaw.ca/ duncancrow/inulin_review.html>. Acesso em: 7 fev. 2011.

69 TUOHY, K.M.; FINLAY, R.K.; WYNNE, A.G.; GIBSON, G.R. A human volunteer study on the prebiotic effects of HP-inulin - faecal bacteria enumerated using fluorescent in situ hybridisation (FISH). Anaerobe, v.7, n.3, p. 113-118, 2001.

70 VAN DEN HEUVEL, E.G.; SCHAAFSMA, G.; MUYS, T.; VAN DOKKUM, W. Nondigestible oligosaccharides do not interfere with calcium and nonheme-iron absorption in young, healthy men. American Journal of Clinical Nutrition, $\mathrm{V}$. 67, n.3, p. 445451, 1998.

71 VAN DEN HEUVEL, E.G.H.; MUYS, T.; VAN DOKKUM, W.; SCHAAFSMA, G. Oligofructose stimulates calcium absorption in adolescents. American Journal of Clinical Nutrition, v. 69, n.3, p. 544-548, 1999.

72 VAN DE WIELE, T.; BOON, N.; POSSEMIERS, S.; JACOBS, H.; VERSTRAETE, W. Inulin-type fructans of longer degree of polymerization exert more pronounced in vitro prebiotic effects. Journal of Applied Microbiology, v. 102, n.2, p. 452460, 2007.

73 VAN DOKKUM, W.; WEZENDONK, B.; SRIKUMAR, T.; VAN DEN HEUVEL, E. Effect of nondigestible oligosaccharides on large-bowel functions, blood lipid concentrations and glucose absorption in young healthy male subjects. European Journal of Clinical Nutrition, v.53, n. 1, p. 1-7, 1999

74 VORAGEN, A.G.J. Technological aspects of functional food-related carbohydrates. Trends in Food Science \& Technology, v.9, n. 8/9, p.328-335, 1998.

75 WILLIAMS, C.M. Effects of inulin on lipid parameters in humans. Journal of Nutrition, v. 129, n.7, p. $1471-1473,1999$. 